\title{
A GROUNDED THEORY APPROACH: INTER-ORGANIZATIONAL RELATIONSHIPS IN COMMUNITY COLLEGE FUNDRAISING
}

\author{
Jacqueline C. Almquist \\ Dr. Rebecca Meisenbach, Dissertation Supervisor
}

\begin{abstract}
As state funding for community colleges dwindle, presidential turnover is predicted, even as demands for educational programs and services increase, fundraisers are left to manage relationships and secure resources for organizational mission and vision fulfillment and sustainability. Community colleges provide a rich context for studying interorganizational relationships (IORs) since fundraising professionals manage multi-layer relationships associated with their organizational role. This unique environment typifies IORs as the college governing board relationship works with the foundation fundraising board relationship in interdependent ways to advance organizational goals. My study presents the Theory of Fundraising Relationship Management (TFRM) as a framework for understanding how fundraising professionals manage the relationships in the inter- organizational community college context. A model operationalizes TFRM and positions the college president-fundraiser dyad as central to the relationship management processes presented in four distinct quadrants: (1) formalizing board interdependence; (2) tailoring interactions; (3) enlisting and educating others; (4) and raising money. The management of these relationships are entrenched with dialectical tensions of empowerment- disempowerment, expression-suppression, and integration-separation. Implications provide researchers and practitioners alike with the communicative processes embedded in fundraising relationship management by adding to the literature and providing an actionable agenda.
\end{abstract}


